Review Article

\title{
Literatur Review Metodologi Pembelajaran Ilmu Pengetahuan Sosial (IPS)
}

\author{
Febri Aris Susanto* \\ Mahasiswa Program Pasca Sarjana, Universitas Islam Negeri Maulana Malik Ibrahim Malang
}

Article history: Received 19 August 2017; Accepted 09 September 2017; Published 30 October 2017

\begin{abstract}
Social Sciences is a subject that studies and discusses social issues in society. The learning process of a subject will take place well and smoothly if the teacher in delivering the material has strategies and methods in delivering it to the students. The purpose of this article is to describe the social science learning methodology from literature review analysis. The method used is to use various literature review on the social science learning methodology. The social science is a field of study in the learning process is expected to provide students to be responsible in social life. Somesocial science learning methodologies are tailored to the conditions of students and facilities available so as to provide good learning outcomes with indicators of mastery and student learning achievement.
\end{abstract}

Keywords: ,metodologic; learning IPS

\begin{abstract}
ABSTRAK
Ilmu Pengetahuan Sosial (IPS) merupakan mata pelajaran yang mempelajari dan membahas masalah sosial di masyarakat. Proses pembelajaran suatu mata pelajaran akan berlangsung dengan baik dan lancar jika guru dalam menyampaikan materi mempunyai strategi dan metode dalam menyampaikannya kepada siswa. Tujuan dari artikel ini adalah mendeskripsikan metodologi pembelajaran IPS dari analisis literature review. Metode yang digunakan adalah menggunakan berbagai literature review mengenai metodologi pembelajaran IPS. IPS merupakan bidang studi dalam proses pembelajarannya diharapkan mampu memberikan siswa untuk dapat bertanggung jawab dalam kehidupan bermasyarakat. Beberapa metodologi pembelajaran IPS disesuaikan dengan kondisi siswa dan fasilitas yang tersedia sehingga mampu memberikan hasil belajar yang baik dengan indikator ketuntasan dan prestasi belajar siswa.
\end{abstract}

Kata kunci : metodologi, pembelajaran IPS

HOW TO CITE: Susanto, Febri Aris. (2017). Metodologi Pembelajaran IPS Pada Pendidikan Dasar, Madrosatuna: Journal of Islamic Elementary School, Vol. 2 (1), 105-114. doi: 10.21070.madrosatuna.v2i1.1847

\section{PENDAHULUAN}

Pendidikan merupakan sebuah kunci dalam memutus rantai kemiskinan. Pendidikan merupakan salah satu upaya dengan kesadaran dan terencana untuk mewujudkan situasi belajar dan proses belajar untuk mendorong siswa dalam mengembangkan potensi mereka secara aktif agar memiliki kekuatan spiritual, kontrol diri, kepribadian, intelektual, karakter mulia, dan keterampilan, bagi diri mereka sendiri, masyarakat, dan Negara (Agung, 2015:51).Dengan adanya pendidikan yang baik dan fasilitas yang memadai, maka dapat

\footnotetext{
*Email: febri.aris@gmail.com

Peer reviewed under reponsibility of Universitas Muhammadiyah Sidoarjo.

(C) 2017 Universitas Muhammadiyah Sidoarjo, All right reserved, This is an open access article under the CC BY license (http://creativecommons.org/licenses/by/4.0/)
} 
meningkatkan keberhasilan belajar siswa. Keberhasilan belajar peserta didik dapat dilihat dari kemampuannya dalam menguasai materi pembelajaran, mendapatan manfaat dari apa yang dipelajari, serta mendapatkan nilai maksimal sebagai prestasi belajarnya (Alifia dan Riani, 2017:21). Prestasi belajar IPS (Ilmu Pengetahuan Sosial) dilihat dari ketercapaian nilai KKM (Kriteria Ketuntasan Minimal) pada mata pelajaran IPS.

IPS merupakan mata pelajaran yang mempelajari, membahas, dan menganalisa masalah sosial di masyarakat dengan meninjau berbagai aspek kehidupan, juga mempersiapkan siswa dalam menguasai dan mengembangkan pengetahuan, sikap, nilai dan kecakapan dasar yang diperlukan bagi kehidupan di masyarakat (Zuraida, 2014:22). IPS atau Social Studies mempunyai tugas mulia dan menjadi fondasi penting bagi pengembangan intelektual, emosional, kultural, dan sosial peserta didik, yaitu mampu menumbuhkembangkan cara berfikir, bersikap, dan berperilaku yang bertanggungjawab selaku individual, warga masyarakat, warga Negara dan warga dunia (Maryani dan Syamsudin, 2009:1). Lanjutnya, bahwa mata pelajaran IPS bertugas mengembangkan potensi peserta didik agar peka terhadap masalah sosial yang terjadi di masyarakat, memiliki sikap mental positif untuk perbaikan segala ketimpangan, dan terampil mengatasi setiap masalah yang terjadi sehari-hari baik yang menimpa dirinya maupun yang terjadi di masyarakat (Maryani dan Syamsudin, 2009:1).

Kunci utama dalam pembelajaran IPS adalah bagaimana membina kecerdasan sosial siswa yang mampu berpikir kritis, analitis, kreatif, inovatif, berwatak dan berkepribadianluhur, bersikap ilmiah dalam cara memandang, menganalisa serta mnelaah kehidupan nyata yang dihadapinya (Badan Standar Nasional Pendidikan, 2006:576). Sehingga untuk mengetahui tingkat keberhasilan peserta didik/ siswa, maka dalam proses pembelajaran diperlukan sebuah konsep/metodologi pembelajarn yang tepat dan sesuai dengan kondisi lingkungan sekolah, baik dari kondisi siswa dan fasilitas yang tersedia bagi proses pembelajaran. Pada artikel ini bertujuan untuk mereview literatur berupa beberapa metodologi pembelajaran IPS. Review Literatur metodologi pembelajaran IPS akan didiskusikan dengan menjelaskan masing-masing metodologi pembelajaran IPS.

\section{PEMBAHASAN}

Proses pembelajaran merupakan proses transfer keilmuan dari guru kepada murid, melalui guru sebagai pusat dalam memberikan materi dan siswa mendengarkan atau 
keduanya mempunyai kontribusi yang sama, dengan adanya diskusi setidaknya siswa mampu menyampaikan pemikirannya melalui diskusi dan tanya jawab.Tujuan pembelajaran adalah perubahan perilaku yang positif dan permanen dari siswa setelah mengikiti pembelajaran (Masnur, 2007). Menurut Suyanto dan Hisyam (2010:81), komponen pembelajaran antara lain: a. tujuan pembelajaran; b. bahan pembelajaran; c. metode pembelajaran; d. media pembelajaran; e. guru dan pendidik; f. siswa; g. penilaian dan evaluasi. Dalam proses pembelajaran yang berorientasi pada keberhasilan dan prestasi siswa, maka terdapat beberapa mtodologi pembelajaran IPS.

\section{Model Pembelajaran Kooperatif Tipe Course Review Horay (CRH).}

Menurut Kursiasih dan Sani (2015), model pembelajaran CRH merupakan model pembelajaran yang dapat menciptakan suasana kelas menjadi meriah dan menyenangkan karena setiap siswa yang dapat menjawab benar maka siswa tersebut diwajibkan berteriak "hore" atau yel-yel lainnya yang disepakati. Model CRH juga merupakan salah satu model pembelajaran kooperatif yang bersifat menyenangkan dan meningkatkan kemampuan siswa dalam berkompetisi secara positif dalam pembelajaran, selain itu juga dapat mengembangkan kemampuan berpikir kritis siswa, serta membantu siswa untuk mengingat konsep yang dipelajari secara mudah (Laksana, 2017).

\section{Strategi Pemecahan Masalah}

Menurut Rosardi (2013:24), proses pemecahan masalah melibatkan tiga jenis berpikir, yaitu analisis, kreatif dan ritis. Lebih lanjutnya, pemecahan masalah pada umumnya melibatkan rancangan cara untuk menjawab pertanyaan dan untuk memenuhi atau menjelaskan suatu situasi yang menyajikan sebuah tantangan, menawarkan peluang atau perhatian (Rosardi, 2013:24). Metode problem solving merupakan pemecahan masalah yang dapat dipandang sebagai manipulasi informasi secara sistematis, langkah demi langkah, dengan mengolah informasi yang diperoleh melalui pengamatan untuk mencapai suatu hasil pemikiran sebagai respon terhadap suatu masalah yang dihadapi (Nasution, 2006:117). Sehingga problem solving membutuhkan kepekaan yang berasal dari kegiatan pengamatan dengan tujuan untuk mengumpulkan berbagai informasi yang diperlukan sehingga mampu menemukan solusi terhadap masalah yang sedang dibahas (Rosardi, 2014:24). 


\section{Pembelajaran Berbasis Masalah}

Pembelajaran berbasis masalah adalah metode yang mengharuskan pelajar untuk menemukan jawabannya tanpa bantuan khusus (Darmawan, 2010:108). Metode pembelajaran ang berbasis masalah menekankan pada proses pemecahan suatu masalah dengan penentuan alternative pemecahan yang paling tepat (Darmawan, 2010:109). Terdapat langkah-langkah dalam pelaksanaan pembelajaran berbasis masalah, yaitu: a. Merumuskan permasalahan; b. Menelaah permasalahan; c. Membuat/merumuskan pemecahan masalah; dan d. Menentukan pilihan pemecahan /kesimpulan. Tabel 1 berikut ini menjelaskan tahap-tahap pengebangan pembelajaran berbasis masalah.

Tabel 1. Tahap-tahapan Pengembangan Pembelajaran Berbasis Masalah

\begin{tabular}{|l|l|}
\hline \multicolumn{1}{|c|}{ Fase-fase } & \multicolumn{1}{|c|}{ Perilaku Guru } \\
\hline Fase1: Orientasi siswa pada masalah & $\begin{array}{l}\text { Guru menjeaskan tujuan pembelajaran, } \\
\text { menjelaskan logistic yang dibutuhkan, } \\
\text { memotivasi siswa-siswa terlibat pada aktivitas } \\
\text { pemecahan masalah. }\end{array}$ \\
\hline Fase 2: Mengorganisasikan siswa untuk belajar & $\begin{array}{l}\text { Guru membantu siswa mendefiniskan dan } \\
\text { mengorganisasikan tugas belajar yang } \\
\text { berhubungan dengan masalah tersebut }\end{array}$ \\
\hline $\begin{array}{l}\text { Fase 3: Membimbing penyelidikan individual } \\
\text { maupun kelompok }\end{array}$ & $\begin{array}{l}\text { Guru mendorong siswa untuk mengumpulkan } \\
\text { informasi yang sesuai, melaksanakan } \\
\text { eksperimen untuk mendapatkan penjelasan dan } \\
\text { pemecahan masalah }\end{array}$ \\
\hline $\begin{array}{l}\text { Fase 4: Mengembangkan dan menyajikan hasil } \\
\text { karya }\end{array}$ & $\begin{array}{l}\text { Guru membantu siswa dalam merencanakan dan } \\
\text { menyiapkan karya yang sesuai seperti laporan, } \\
\text { dan membantu mereka untuk berbagi tugas } \\
\text { dengan temannya }\end{array}$ \\
\hline $\begin{array}{l}\text { Fase 5: Menganalisis dan mengevaluasi proses } \\
\text { pemecahan masalah }\end{array}$ & $\begin{array}{l}\text { Guru membantu siswa untuk melakukan refleksi } \\
\text { atau evaluasi terhadap penyelidikan mereka dan } \\
\text { proses yang mereka gunakan. }\end{array}$ \\
\hline
\end{tabular}

Sumber: Darmawan, 2010, "Penggunaan Pembelajaran Berbasis Masalah dalam Meningkatkan Kemampuan Berpikir Kritis Siswa Pada Pembelajaran IPS di MI Darrusaadah Pandeglang

\section{Strategi Peta Konsep}

Peta Konsep membuat informasi abstrak menjadi konkret dan sangat bermanfaat meningkatkan ingatan suatu konsep pembelajaran (Yuliani, 2017:194). Lebih lanjut, menurut Yuliani (2017:194), peta konsep juga merupakan strategi yang menyenangkan karena imajinasi dan kreativitas seseorang tidak terbatas dalam membuat peta konsep dan seorang guru juga dapat melakukan evaluasi terhadap penguasaan siswa atas materimateri 
pembelajaran. Menurut Munthe (2009:16), concept map atau peta konsep tidak hanya menggambarkan satu arti hubungan di antara konsep, tetapi juga tingkat dan kualitas pemahaman si pembuat tentang topik. Menurut DePorter \& Hernacki (2006: 172) yaitu bahwa peta konsep dapat memusatkan perhatian, dapat berkonsentrasi pada gagasan-gagasan materi yang dibahas.Langkah-langkah membuat peta konsep di atas sesuai dengan pendapat dari Arends (Trianto, 2012: 160), yaitu: mengidentifikasi ide pokok atau prinsip yang melingkupi sejumlah konsep; mengidentifikasi ide-ide atau konsep-konsep sekunder yang menunjang ide utama; tempatkan ide-ide utama di tengah atau di puncak peta tersebut; dan kelompokkan ide-ide sekunder di sekeliling ide utama yang secara visual menunjukkan hubungan ide-ide tersebut dengan ide utama.

\section{Pendidikan Karakter}

Pendidikan adalah usaha sadar dan terencana untuk mewujudkan suasana belajar dan proses pembelajaran agar peserta didik secara aktif mengembangkan potensi dirinya untuk memiliki kekuatan spiritual keagamaan, pengendalian diri, kepribadian, kecerdasan, akhlak mulia, serta keterampilan yang diperlukan dirinya, masyarakat, bangsa dan Negara (Depdiknas, 2003).

Pendidikan karakter adalah suatu sistem pendidikan dengan penanaman nilai-nilai sesuai dengan budaya bangsa dengan komponen aspek pengetahuan (cognitive), sikap perasaan (affection felling), dan tindakan, baik terhadap Tuhan Yang Maha Esa (YME) baik untuk diri sendiri, masyarakan dan bangsanya (Afandi, 2011: 88). Pendidikan karakter sejalan dengan tujuan pendidikan IPS yaitu membina anak didik menjadi warga negara yang baik, yang memiliki pengetahuan, keterampilan dan kepedulian sosial yang berguna bagi dirinya sendiri serta bagi masyarakat dan bagi negara. Untuk merealisasikan tujuan tersebut, proses mengajar dan membelajarkannya, tidak hanya terbatas pada aspek-aspek pengetahuan (kognitif) dan keterampilan (psikomotor) saja, melainkan juga meliputi aspek akhlak (afektif) serta bertanggung jawab sesuai yang terkandung dalam nilai-nilai Pancasila (Sumaatmadja, 2007). Pendidikan karakter dapat dimaknai sebagai pendidikan budi pekerti yaitu yang melibatkan aspek pengetahuan (cognitive), sikap perasaan (affection felling), dan tindakan (Afandi, 2011:92-93). Lebih lanjut, Afandi (2011:93) menyatakan bahwa dengan pendidikan karakter yang diterapkan secara sistematis dan berkelanjutan, seorang peserta didik akan menjadi cerdas emosinya. Kecerdasan emosi ini adalah bekal penting menyongsong anak 
dalam meraih masa depan, karena seseorang akan lebih mudah dan berhasil menghadapi segala macam tantangan kehidupan, termasuk tantangan untuk berhasil secara akademis. Sehingga perilaku seseorang yang berkarakter pada hakekatnya merupakan perwujudan fungsi totalitas psikologis yang mencakup seluruh potensi individu manusia (kognitif, afektif, konatif, dan psikomotorik) dan fungsi totalitas sosial kultural dalam konteks interaksi (dalam keluarga, satuan pendidikan, dan masyarakat) dan berlangsung sepanjang hayat (Depdiknas, 2003).

\section{Social Engagement Method}

Metode ini akan mendorong aktivitas siswa untuk membuat ringkasan atau resume atau review berdasarkan materi yang telah dipelajari juga mengarahkan siswa untuk biasa mengekspresikan ide mereka sendiri juga mendengarkan dan berkomentar orang lain yang berbicara dengan penuh perhatian (Maulana, dkk, 2017 :9). Social Engagement (keterlibatan sosial) adalah perancangan pembelajaran yang memadukan pembelajaran ICT (Information communication technology) dengan role play dan metode script cooperatif untuk meningkatkan aktivitas siswa sekolah dasar dalam studi sosial (Maulana, dkk, 2017:1).Jadi, Social Engagenemt Methodbisa menjadi model pembelajaran yang menyenangkan dan menarik bagi siswa, mereka bisa lebih tertarik untuk belajar tentang studi sosial (Maulana, dkk,2017:9) Menurt Maulana dkk (2017:9) terdapat beberapa langkah-langkah implementasi engagement social: 1. Siswa membagi ke dalam kelompok dengan teman lain (1-5 anak-anak setiap kelompok). 2. Pada permulaan, siswa diawasi materi studi sosial yang akan dipelajari dengan metode pembelajaran TIK, menggunakan komputer di sekolah atau di laboratorium komputer. 3. Setelah menonton materi, siswa duduk dalam lingkaran atau persegi untuk membuat kelompok dan memainkan peran atau mendramatisasi dari bahan yang diberikan (Role Play). 4. Selanjutnya, siswa diarahkan untuk memberi umpan balik dengan yang lain tentang materi resume atau ringkasan yang telah mereka pelajari (Cooperative Script).

\section{Contextual Teaching and Learning}

Pendekatan Pengajaran kontekstual merupakan salah satu pendekatan pembelajaran yang mampu melibatkan sistwa ke dalam proses pembelajaran dengan dunia nyata yang dapat meningkatkan kesadaran diri terhadap lingkungan sosial, nilai moral siswa dan mempu menggali potensi yang dimiliki oleh siswa (Sama, dkk, 2017: 431). Menurut Trianto 


\begin{tabular}{|c|c|c|c|c|c|c|c|}
\hline No & $\begin{array}{c}\text { Penulis/ } \\
\text { Tahun }\end{array}$ & Judul & $\begin{array}{l}\text { Metodologi } \\
\text { Pembelajaran }\end{array}$ & Metode & $\begin{array}{c}\text { Metode } \\
\text { Pengumpula } \\
\text { n Data }\end{array}$ & $\begin{array}{c}\text { Metode } \\
\text { Analisa } \\
\text { Data }\end{array}$ & Hasil \\
\hline 1 & $\begin{array}{l}\text { Tri Satya } \\
\text { Laksana } \\
(2017)\end{array}$ & 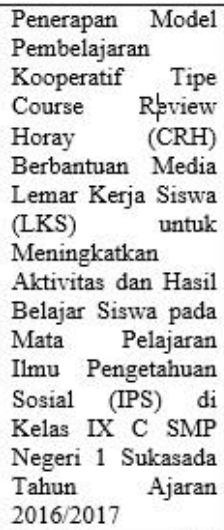 & $\begin{array}{l}\text { Model } \\
\text { Pembelajaran } \\
\text { Kooperatif Tipe } \\
\text { Course Review } \\
\text { Horay (CRH) }\end{array}$ & $\begin{array}{l}\text { Penelitian } \\
\text { Tindakan Kelas } \\
(\mathrm{PTK}) \text { dua } \\
\text { siklus dengan } \\
\text { responden siswa } \\
\text { kelas IX C } \\
\text { Negeri } \\
\text { Sukasada }\end{array}$ & $\begin{array}{l}\text { Observasi, } \\
\text { data hasil } \\
\text { belajar } \\
\text { (dengan tes) }\end{array}$ & $\begin{array}{l}\text { Analisa } \\
\text { deskriptif } \\
\text { kuantitatif }\end{array}$ & $\begin{array}{l}\text { (1) penerapan model pembelajaran } \\
\text { kooperatif tipe CRH dapat } \\
\text { meningkatkan aktivitas belajar } \\
\text { siswa yang ditunjukkan dengan } \\
\text { rata-rata skor aktivitas belajar siklus } \\
\text { I sebesar } 13,93 \text { dengan kategori } \\
\text { cukup aktif selanjutnya meningkat } \\
\text { menjadi } 17,18 \text { dengan kategori aktif } \\
\text { pada siklus II. (2) penerapan model } \\
\text { pembelajaran kooperatif tipe CRH } \\
\text { dapat meningkatkan hasil belajar } \\
\text { siswa yang ditunjukkan dengan } \\
\text { ratarata skor hasil belajar siklus I } \\
\text { sebesar } 73,83 \text { dengan kategori } \\
\text { cukup selanjutnya meningkat } \\
\text { menjadi } 80,88 \text { dengan kategori baik } \\
\text { pada siklus II. }\end{array}$ \\
\hline 2 & $\begin{array}{l}\text { Raras } \\
\text { Gistha } \\
\text { Rosardi } \\
\text { (2013) }\end{array}$ & $\begin{array}{l}\text { Pembelajaran IPS } \\
\text { dengan Strategi } \\
\text { Pemecahan } \\
\text { Masalah untuk } \\
\text { Meningkatkan } \\
\text { Kemandirian dan }\end{array}$ & $\begin{array}{l}\text { Strategi } \\
\text { Pemecahan } \\
\text { Masalah }\end{array}$ & $\begin{array}{l}\text { Eksperiment } \\
\text { semu dengan } \\
\text { responden } \\
\text { semua siswa } \\
\text { SPM } \\
\text { Muhammadiyah }\end{array}$ & $\begin{array}{l}\mathrm{Uji} \quad \text { coba } \\
\text { instrument } \\
\text { (tes) melalui } \\
\text { angket dan } \\
\text { hasil belajar } \\
\text { kognitif }\end{array}$ & $\begin{array}{l}\text { Uji } \\
\text { validasi } \\
\text { dan } \\
\text { reliability } \\
\text { dengan } \\
\text { SPSS 16, }\end{array}$ & $\begin{array}{l}\text { 1). Strategi pembelajaran pemecah } \\
\text { masalah dan strategi pembelajaran } \\
\text { konvensional menunjukkan } \\
\text { perbedaan terhadap hasil belajar, } \\
\text { nilai kemandirian dan kepedulian } \\
\text { secara bersama-sama. 2) peneranan }\end{array}$ \\
\hline
\end{tabular}

\begin{tabular}{|c|c|c|c|c|c|c|c|}
\hline & & Kepedulian Siswa & & $\begin{array}{l}2 \\
\text { Sleman DIY }\end{array}$ & $\begin{array}{l}\text { dengan } \\
\text { strategi } \\
\text { pemecahan } \\
\text { masalah } \\
\text { sebagai } \\
\text { variabel } \\
\text { bebas, dan } \\
\text { variabel } \\
\text { terikatnya } \\
\text { yaitu } \\
\text { kemandirian } \\
\text {, kepedulian, } \\
\text { hasil belajar } \\
\text { kognitif }\end{array}$ & $\begin{array}{l}\text { dengan } \\
\text { teknik } \\
\text { analisis } \\
\text { statistic } \\
\text { deskriptif } \\
\text { dan } \\
\text { MANOV } \\
\text { A. }\end{array}$ & $\begin{array}{l}\text { strategi pembelajaran pemecahan } \\
\text { masalah dan strategi pembelajaran } \\
\text { konvensio nal menunjukkan } \\
\text { perbedaan terhadap hasil belajar. 3) } \\
\text { penerapan strategi pembelajaran } \\
\text { pemecahan masalah dan strategi } \\
\text { pembelajaran } 4 \text { konvensional } \\
\text { menunjukkan perbedaan terhadap } \\
\text { nilai kemandirian. 4) penerapan } \\
\text { strategi pembelajaran pemecahan } \\
\text { masalah dan strategi pembelajaran } \\
\text { konvensional menunj }\end{array}$ \\
\hline 3 & $\begin{array}{l}\text { Darmawan } \\
(2010)\end{array}$ & \begin{tabular}{l}
\multicolumn{2}{l}{ Penggunaan } \\
Pembelajaran \\
Berbasis Masalah \\
dalam \\
Meningkatkan \\
Kemampuan \\
Berpikir Kritis \\
Siswarrada \\
Pembelajaran IPS \\
di MI Darrusaadah \\
Pandeglang
\end{tabular} & $\begin{array}{l}\text { Pembelajaran } \\
\text { Berbasis } \\
\text { Masalah }\end{array}$ & $\begin{array}{l}\text { Penelitian } \\
\text { Tindakan Kelas } \\
3 \text { siklus, Siswa } \\
\text { Kelas V MI } \\
\text { Darrusaadah } \\
\text { Pandeglang }\end{array}$ & $\begin{array}{l}\text { Observasi } \\
\text { dan tes }\end{array}$ & $\begin{array}{l}\text { Statistik } \\
\text { deskriptif }\end{array}$ & $\begin{array}{l}\text { Penelitian menemukan berbaga } \\
\text { dimensi pembelajaran IPS, kinerja } \\
\text { guru dan siswa yang dapat } \\
\text { meningkatkan iklim } \quad \text { sosial } \\
\text { pembelajaran IPS SD dan } \\
\text { memberikan rekomendasi yang } \\
\text { diperlukan baik bersiffat konseptual } \\
\text { tentang pembelajaran IPS SD } \\
\text { maupun yang bersifat praktis. }\end{array}$ \\
\hline 4 & $\begin{array}{l}\text { Dian } \\
\text { Yuliani } \\
(2017)\end{array}$ & $\begin{array}{l}\text { Penerapaan Strategi } \\
\text { Peta Konsep untuk } \\
\text { Meningkatkan } \\
\text { Aktivitas dan Hasil } \\
\text { Belajar IPS Siswa } \\
\text { Kelas V SD }\end{array}$ & $\begin{array}{ll}\text { Strategi } & \text { Peta } \\
\text { Konsep } & \end{array}$ & $\begin{array}{lr}\text { PTK } & \text { dengan } \\
\text { model } & \text { Kemmis } \\
\text { dan Taggart. } \\
\text { Responden } \\
\text { siswa kelas V } \\
\text { SD Kotagede } 5 \\
\text { Yogyakarta } \\
\end{array}$ & $\begin{array}{l}\text { Metode Tes } \\
\text { dan } \\
\text { Observasi }\end{array}$ & $\begin{array}{l}\text { Statistik } \\
\text { Deskriptif }\end{array}$ & $\begin{array}{l}\text { Hasil penelitian menunjukkan } \\
\text { bahwa aktivitas dan hasil belajar } \\
\text { IPS siswa kelas V dapat meningkat } \\
\text { menggunakan strategi peta konsep } \\
\text { baik secara berkelompok maupun } \\
\text { berpasangan. Hal tersebut } \\
\text { ditunjukkan dengan aktivitas siswa }\end{array}$ \\
\hline
\end{tabular}




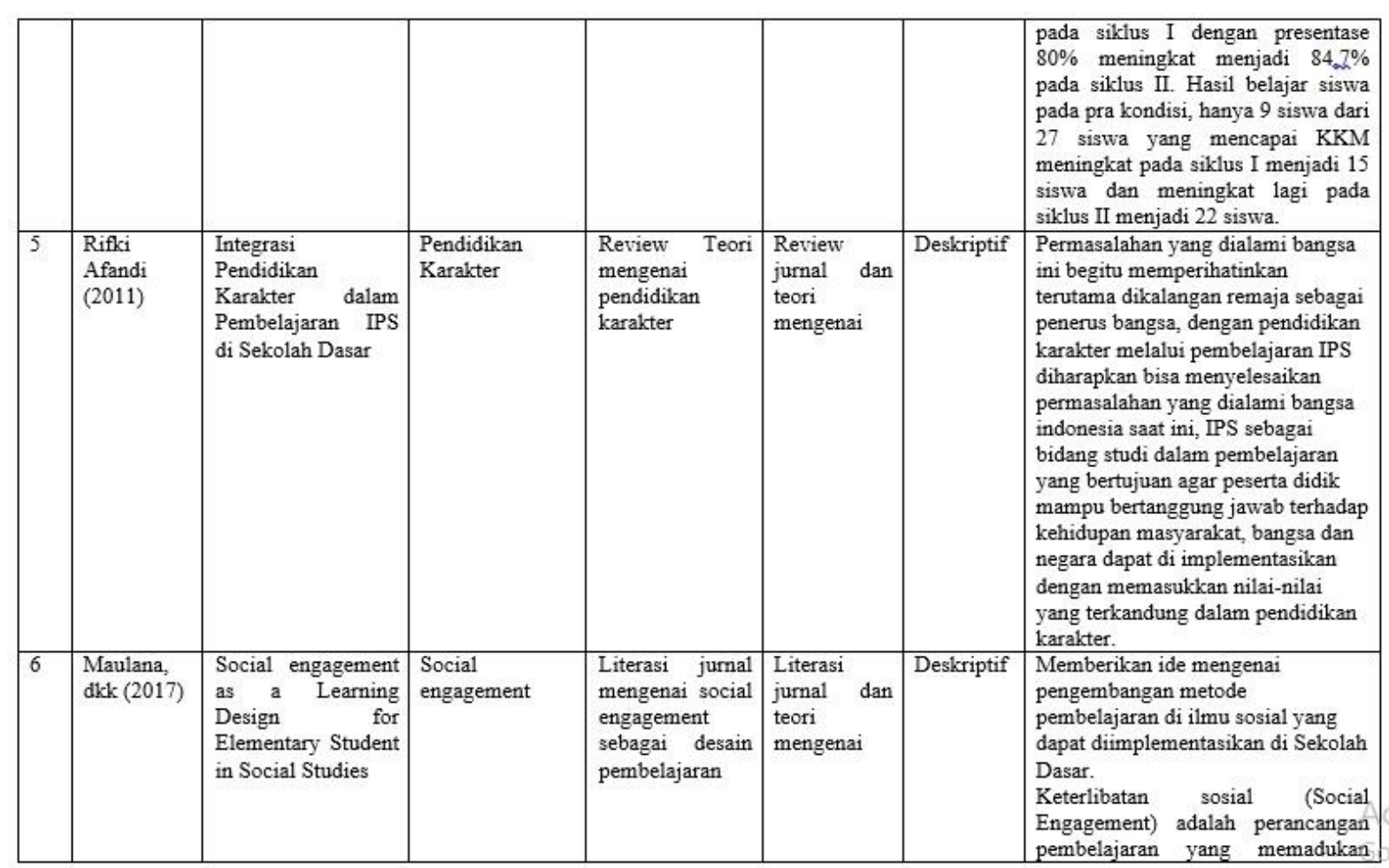

\begin{tabular}{|c|c|c|c|c|c|c|c|}
\hline & & & & & & & $\begin{array}{l}\text { pembelajaran ICT (Information } \\
\text { communication technology) dengan } \\
\text { role play dan metode script koperasi } \\
\text { untuk meningkatkan aktivitas siswa } \\
\text { sekolah dasar dalam studi sosial. }\end{array}$ \\
\hline 7 & $\begin{array}{l}\text { Sama dkk } \\
(2017)\end{array}$ & $\begin{array}{l}\text { Implementasi } \\
\text { Pendekatan CTL } \\
\text { pada Pembelajaran } \\
\text { IPS untuk } \\
\text { meningkatkan Hasil } \\
\text { Belajar Siswa Keas } \\
\text { IV SD }\end{array}$ & $\begin{array}{l}\text { Contextual } \\
\text { Teaching and } \\
\text { Learning }\end{array}$ & $\begin{array}{l}\text { Penelitian } \\
\text { Tindakan Kelas } \\
\text { dengan } 3 \text { siklus. } \\
\text { Responden } \\
\text { Siswa Kelas IV } \\
\text { SDS Taman } \\
\text { Muda Kalianget, } \\
\text { Sumenep }\end{array}$ & $\begin{array}{l}\text { Lembar } \\
\text { Aktivitas } \\
\text { Siswa dan } \\
\text { Hasil } \\
\text { Belajar }\end{array}$ & Deskriptif & $\begin{array}{l}\text { Penerapan pembelajaran } \begin{array}{r}\text { dengan } \\
\text { pendekatan } \text { CTL } \\
\text { meningkatkan aktivitas belajar }\end{array} \\
\text { siswa dalam pembelajaran IPS dan } \\
\text { Hasil belajar siswa kelas IV SDS } \\
\text { Taman Muda Kalianget Sumenep } \\
\text { pada pembelajaran IPS denagn } \\
\text { pendekatan CTL mengalami } \\
\text { peningkatan secara signifikan. } \\
\text { Indikator keberhasilan terdapat pada } \\
\text { siklus III dimana nilai rata-rata } \\
\text { siswa adalah } 74 \text { dan prosentase } \\
\text { ketuntasan klasikan mencapai } 90 \% \text {. }\end{array}$ \\
\hline
\end{tabular}

\section{KESIMPULAN}

IPS merupakan bidang studi dalam proses pembelajarannya diharapkan mampu memberikan siswa untuk dapat bertanggung jawab dalam kehidupan bermasyarakat. Beberapa metodologi pembelajaran IPS disesuaikan dengan kondisi siswa dan fasilitas yang tersedia sehingga mampu memberikan hasil belajar yang baik dengan indikator ketuntasan dan prestasi belajar siswa. 


\section{REFERENSI}

Agung, L.S. 2015. The Development of Local Wisdom-Based Social Science Learning Model with Bengawan Solo as Learning Source. American International Journal of Social. Science. VOl.4.No.4.

Alifia., Dian., Riani Hanifah., 2017., Hubungan Antara Komunikasi Interpersonal Guru dan Minat Belajar Dengan Prestasi Belajar IPS Siswa di SMP Negeri 74 Jakarta., Edukasi IPS., Vol.1. No.1

Darmawan. 2010. Penggunaan Pembelajaran Berbasis Masalah dalam Meningkatkan Kemampuan Berpikir Kritis Siswa Pada Pembelajaran IPS di MI Darrusaadah Pandeglang. Jurnal Penelitian Pendidikan Vol.11. No.2

Depdiknas 2003. Undang-undang Nomor 20 Tahun 2003 tentang Sistem Pendidikan Nasional, Jakarta: Depdiknas

DePorter, Bobbi \& Hernacki, Mike. 2006. Quantum Learning: Unleashing the Genius In You ( Quantum Learning: Membiasakan Belajar Nyaman dan Menyenangkan). Penerjemah: Alwiyah Abdurrahman. Bandung: PT Mizan Pustaka

Kurniasih, Imas dan Berlin Sani. 2015. Ragam Pengembangan Model Pembelajaran Untuk Peningkatan Profesionalitas Guru. Yogyakarta: Kata Pena

Laksana, Satya T., 2017., Penerapam Model Pembelajaran Kooperatif Tipe Course Review Horay (CRH) Berbantuan Media Lemar Kerja Siswa (LKS) untuk Meningkatkan Aktivitas dan Hasil Belajar Siswa pada Mata Pelajaran Ilmu Pengetahuan Sosial (IPS) di Kelas IX C SMP Negeri 1 Sukasada Tahun Ajaran 2016/2017., e-Journal Jurusan Pendidikan Ekonomi., Vol.9., No.1

Maryani. E., Syamsudin.H. 2009. Pengembangan Program Pembelajaran IPS untuk Meningkatkan Kompetensi Ketrampilan Sosial. Jurnal Penelitia. Vol.9. No.1.

Maulana. A., dkk. 2017. Social engagement as a Learning Design for Elementary Student in Social Studies. International Conference on Literature, Humanities and Social Science, Jan. 23-24, 2017, Manila (Philippines).

Munthe, Bermawy. (ed). 2009. Desain Pembelajaran. Yogyakarta: PT Pustaka Insani Madani

Muslich, Masnur. 2007. KTSP Pembelajaran Berbasis Kompetensi dan Kontekstual. Jakarta: PT. Bumi Aksara

Nasution. 2006. Kurikulum dan Pengajaran., Jakarta: Bumi Aksara

Rifki Afandi. 2011. Integrasi Pendidikan Karakter dalam Pembelajaran IPS di Sekolah Dasar. Pedagogia. Vol. 1. No.1

Rosardi, Gistha , Raras., 2013. Pembelajaran IPS dengan Strategi Pemecahan Masalah untuk Meningkatkan Kemandirian dan Kepedulian Siswa., Socia Jurnal Ilmu-ilmu Sosial.,Vol.10., No.1

Sama, dkk. 2017. Implementasi Pendekatan CTL pada Pembelajaran IPS untuk meningkatkan Hasil Belajar Siswa Kelas IV SD. Jurnal Review Pendidikan Dasar: JUrnal Kajian Pendidikan dan Hasil Penelitian. Vol.3. No.2. e-ISSN: 2460-8475.

Sumaatmadja, Nursid. 2007 Konsep Dasar IPS. Modul 1-2. Jakarta: Universitas Terbuka 
Suyanto dan Djihad Hisyam. 2010. Pendidikan Indonesia Memasuki Milenium III. Yogyakarta: Adicita Karya Nusa.

Trianto. 2009. Model-model Pembelajaran Inovatif Berorientasi Konstruktivistik. Jakarta:Kencana.

Trianto. 2012. Mendesain Model Pembelajaran Inovatif-Progresif: Konsep, Landasan, dan Implementasinya pada Kurikulum Tingkat Satuan Pendidikan (KTSP). Jakarta: Kencana Prenada Media Group.

Yuliani, Dian. 2017. Penerapaan Strategi Peta Konsep untuk Meningkatkan Aktivitas dan Hasil Belajar IPS Siswa Kelas V SD. Jurnal Pendidikan Guru Sekolah dasar Edisi 3 Tahun ke-6.

Zuraida., 2014., Penggunaan Model Problem Solvong dalam Pembelajaran IPS di Sekolah Dasar., Pedagogi, Jurnal Ilmiah Ilmu Pendidikan., Volume XIV, No.2. 